\title{
O estudo dirigido como estratégia de ensino da educação profissional e tecnológica:
}

\section{singularidades e perspectivas}

Directed study as a teaching strategy in professional and technological education: singularities and perspectives

El estudio dirigido como estrategia didáctica en la formación profesional y tecnológica: singularidades y perspectivas

Recebido: 04/09/2021 | Revisado: 11/09/2021 | Aceito: 14/09/2021 | Publicado: 16/09/2021

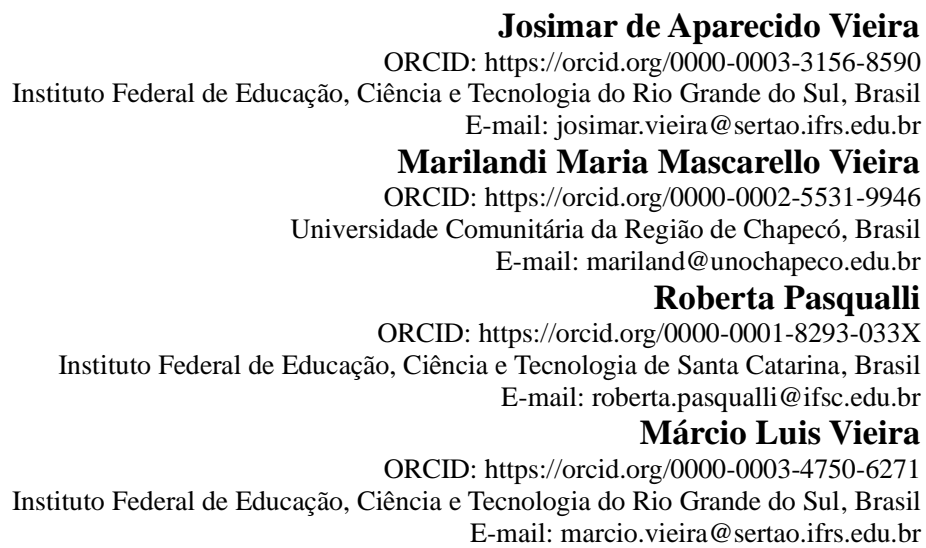

\section{Resumo}

Este ensaio analisa o estudo dirigido como estratégia de ensino para a Educação Profissional e Tecnológica (EPT), apontando singularidades, efeitos no processo ensino-aprendizagem e procedimentos para sua implementação. Constituído numa abordagem qualitativa e dialética, foi produzido seguindo os tipos de pesquisa exploratória e descritiva por meio da pesquisa bibliográfica concentrada em obras de autores como Anastasiou e Alves, Araujo, Bordenave e Pereira, Kuenzer, Libâneo, Machado, Nérici, Piletti, Veiga, entre outros. Por se tratar de tema extenso, a produção incidiu nas seguintes indagações: a) que singularidades podem ser apontadas no estudo dirigido como estratégia de ensino na EPT? b) quais os efeitos do estudo dirigido no processo ensino-aprendizagem da EPT? c) como planejar o estudo dirigido a ser aplicado na EPT? e d) que procedimentos são necessários para implementar o estudo dirigido na EPT? As repercussões do trabalho indicam que o estudo dirigido é uma estratégia que pode ser empregada na EPT, contribuindo para inovar o processo ensino-aprendizagem, favorecendo o desenvolvimento de uma pedagogia em que o estudante é o centro das atividades, desenvolvendo temas de seu interesse, aprendendo a aprender, descobrindo o prazer para aprender e sendo sujeito de suas ações.

Palavras-chave: Ensino; Educação profissional e tecnológica; Estratégias de ensino; Estudo dirigido.

\begin{abstract}
This essay analyzes the directed study as a teaching strategy for Professional and Technological Education (EFA), pointing singularities, effects on the teaching-learning process and procedures for its implementation. Constituted in a qualitative and dialectical approach, it was produced following the exploratory and descriptive research types through bibliographic research concentrated in works by authors such as Anastasiou and Alves (2015), Araujo (n.d.), Bordenave and Pereira (2014), Kuenzer (2014), Libâneo (2018), Machado (2008), Nérici (1992), Piletti (2010), Veiga (2017), among others. Because it is an extensive theme, the production focused on the following questions: a) what singularities can be pointed out in the directed study as a teaching strategy in EFA? b) what are the effects of the directed study in the teaching-learning process of EFA? c) how to plan the directed study to be applied in EFA? and d) what procedures are necessary to implement the directed study in EFA? The repercussions of the work indicate that directed study is a strategy that can be employed in EFA, contributing to innovate the teaching-learning process, favoring the development of a pedagogy in which the student is the center of activities, developing themes of his interest, learning to learn, discovering the pleasure of learning, and being the subject of his actions.
\end{abstract}

Keywords: Teaching; Vocational and technological education; Teaching strategies; Directed study. 


\begin{abstract}
Resumen
Este ensayo analiza el estudio dirigido como estrategia didáctica para la Educación Profesional y Tecnológica (EPT), señalando singularidades, efectos en el proceso de enseñanza-aprendizaje y procedimientos para su implementación. Constituido en un enfoque cualitativo y dialéctico, fue producido siguiendo los tipos de investigación exploratoria y descriptiva a través de la investigación bibliográfica centrada en trabajos de autores como Anastasiou y Alves (2015), Araujo (s.f.), Bordenave y Pereira (2014), Kuenzer (2014), Libâneo (2018), Machado (2008), Nérici (1992), Piletti (2010), Veiga (2017), entre otros. Por tratarse de un tema extenso, la producción se centró en las siguientes preguntas: a) ¿qué singularidades se pueden señalar en el estudio dirigido como estrategia de enseñanza en la EPT? b) ¿cuáles son los efectos del estudio dirigido en el proceso de enseñanza-aprendizaje de la EPT? c) ¿cómo planificar el estudio dirigido para aplicarlo en la EPT? y d) ¿qué procedimientos son necesarios para implementar el estudio dirigido en la EPT? Las repercusiones del trabajo indican que el estudio dirigido es una estrategia que puede ser empleada en la EPT, contribuyendo a innovar el proceso de enseñanza-aprendizaje, favoreciendo el desarrollo de una pedagogía en la que el alumno es el centro de las actividades, desarrollando temas de su interés, aprendiendo a aprender, descubriendo el placer de aprender y siendo sujeto de sus acciones.
\end{abstract}

Palabras clave: Enseñanza; Educación profesional y tecnológica; Estrategias de enseñanza; Estudio dirigido.

\title{
1. Introdução
}

Ao se pensar sobre os meios que são utilizados no processo ensino-aprendizagem em instituições de ensino de Educação Profissional e Tecnológica (EPT), alguns questionamentos surgem que demandam estudos. Um primeiro cuidado se direciona aos termos utilizados por professores para se referirem aos meios que utilizam, geralmente denominados de estratégias, técnicas ou dinâmicas.

Nesta direção, Anastasiou e Alves (2015, p. 68-69) destacam que:

Estratégias: do grego estrategía e do latim strategia é a arte de aplicar ou explorar os meios e condições favoráveis e disponíveis com vista à consecução de objetivos específicos.

Técnics: do grego, technikós, relativo a arte. A arte material ou o conjunto de processos de uma arte, maneira, jeito ou habilidade especial de executar ou fazer algo.

Dinâmicas: do grego dinamikós, respeitante ao movimento e as forças, ou organismo em atividade ou, ainda, parte da mecânica que estuda os movimentos.

Essas autoras apontam ainda que tendo em vista essas citações, é possível constatar ênfase na atividade artística. Isso requer dos professores no desenvolvimento das aulas: criatividade, percepção aguçada, vivência pessoal, profunda, renovadora e capacidade de praticar uma ideia a partir do domínio do objeto trabalhado (Anastasiou e Alves, 2015).

Diante dessas considerações, a compreensão das estratégias, técnicas ou dinâmicas utilizadas durante as aulas pode ocorrer de diferentes maneiras e podem ser utilizadas em inúmeras situações. A escolha por um ou outro meio exige do professor uma tomada de decisão que, na maioria das vezes, é uma decisão política que vem eivada de valores, de escolhas, de concepções e de prerrogativas, as quais apontam direções. "Envolvem ainda as relações professor-aluno; aluno-aluno e alunoconsigo mesmo, imprescindíveis ao desenvolvimento do cognitivo para o aprender e o ensinar" (Okane, 2004, p. 21).

Essas decisões estão intimamente ligadas também com a concepção de ensino e aprendizagem que serve de norte ao trabalho docente, já que, segundo Libâneo (2002) professores mais progressistas tendem a preocupar-se mais em organizar o processo de ensino de modo a atender as diferenças individuais e sociais dos alunos e, para isso, estreitam os laços de relacionamento com os alunos, incentivando o diálogo e o debate e tendem a variar os métodos de ensino, inserindo atividades grupais e estudos independentes. Entretanto, adverte o autor que:

Mesmo utilizando técnicas ativas e respeitando mais o aluno, fica a atividade pela atividade, sem considerar que a aprendizagem significa a elaboração dos conhecimentos pela atividade mental do aluno. Em outras palavras, muitos professores não sabem como ajudar o aluno a, através de uma atividade mental, elaborar de forma consciente e independente o conhecimento. As atividades que organizam não levam os alunos a adquirir métodos de pensamento, 
habilidades e capacidades mentais para poderem lidar de forma independente e criativa com os conhecimentos que vão assimilando (Libâneo, 2002, p. 4).

Voltando-se para a EPT, este processo se torna ainda mais complexo e desafiador pelo fato que esta modalidade de ensino está integrada aos diferentes níveis e modalidades de educação e às dimensões do trabalho, da ciência e da tecnologia e tem como função social a educação tecnológica, entendida de forma ampla e universal "[...] buscando o desenvolvimento integral do trabalhador, priorizando a formação de uma consciência crítica, o domínio de princípios científicos e tecnológicos, o desenvolvimento das habilidades socioafetivas, cognitivas e éticas" (Burnier et al, 2007, p. 353).

Para se ter uma ideia da abrangência da EPT, vale destacar o art. 39, § $2^{\circ}$ da LDB - Lei n ${ }^{\circ}$ 9.394, de 20 de dezembro de 1996, onde consta que a EPT “Abrangerá os seguintes cursos: I - de formação inicial e continuada ou qualificação profissional; II - de educação profissional técnica de nível médio; III - de educação profissional tecnológica de graduação e pós-graduação" (Brasil, 1996, p. 17). Isso demonstra a sua dimensão, que inclui desde os cursos de educação superior - os de tecnologia - até a capacitação profissional, e em todos os níveis, modalidades e formas de oferecimento da EPT a utilização de estratégias, técnicas ou dinâmicas está presente.

Somado a isso, Araujo (s.d.) destaca que, no atual debate acerca da educação profissional, tem sido presente a visão dicotômica que separa e distingue a profissionalização da escolarização ou concebe a profissionalização e a escolarização como uma "soma". Esta visão dicotômica também se revela na separação entre as disciplinas teóricas e as disciplinas práticas, entre os saberes que desenvolveriam o pensar e outros que desenvolveriam as capacidades de fazer (Araujo, s.d.).

Para este mesmo autor, uma possível resistência a esta visão se encontra numa outra perspectiva fundada na ideia de unidade, que pressupõe a indissolubilidade entre teoria e prática fundada em:

. A formação do homem em suas amplas capacidades (teórico-práticas) como principal referência pedagógica;

- A teoria e a prática educativa constituiriam o núcleo articulador da formação profissional;

- A teoria sendo sempre revigorada pela prática educativa;

- A prática educacional sendo o ponto de partida e de chegada;

- A ação docente se revelaria a partir da prática concreta e da realidade social;

- O currículo assumiria características teórico-práticas (Araujo, s.d., p. 06).

Diante desta perspectiva, o professor da EPT “[...] deverá ser um verdadeiro estrategista, o que justifica a adoção do termo estratégia, no sentido de estudar, selecionar, organizar e propor as melhores ferramentas facilitadoras para que os estudantes se apropriem do conhecimento" (Anastasiou e Alves, 2015, p. 69). Assim, pressupostos metodológicos que auxiliam na educação dos trabalhadores e, portanto, são objeto de estudos no campo da educação profissional estão expressos em Kuenzer (2004), Machado (2010) e Ramos (2014), dentre outros.

Para auxiliar nesta tarefa, está delineada a temática deste ensaio que, partindo do pressuposto da importância das estratégias, técnicas ou dinâmicas de ensino e as singularidades que cercam a EPT, busca compreender o estudo dirigido como estratégia de ensino, apontando efeitos no processo ensino-aprendizagem e procedimentos para planejá-lo e implementá-lo, fundamentando-se em apontamentos de autores/pesquisadores que abordam da temática, constituindo-se numa investigação do tipo bibliográfica.

Tomando as contribuições de Anastasiou e Alves (2015), este ensaio tem a pretensão de ser um tanto provocador e animador. Provocador, pois quanto mais se procura compreendê-lo, mais se descobre o quanto se tem que aprender sobre ele, e animador porque possibilita, a cada momento, a tentativa de romper com os atuais limites de sua compreensão.

Considerando que esta pretensão é abrangente, a produção deste ensaio foi orientada para responder a seguintes questões: como deve ser compreendido o estudo dirigido como estratégia de ensino na EPT? quais seus efeitos no processo ensino-aprendizagem da EPT? e como planejar e implementar o estudo dirigido na EPT? 
Destarte, intenta-se ampliar o debate acerca da utilização do estudo dirigido como uma das estratégias capazes de contribuir para aproximar teoria e prática (ideia de unidade) nesta modalidade de ensino. Para isso, está organizado em quatro partes, conforme segue: inicia compreendendo a contribuição do estudo dirigido como estratégia de ensino na EPT; na segunda parte aponta efeitos do uso do estudo dirigido no processo ensino-aprendizagem da EPT e na sequência (terceiro e quarto momentos) são esboçados procedimentos para planejamento e implementação que podem ser seguidos para utilização dessa estratégia de ensino na EPT e por fim, apresenta as considerações finais deste estudo.

\section{Percurso Metodológico}

Considerando seu propósito, este estudo se caracteriza como pesquisa exploratória e descritiva onde busca-se maior familiaridade com a temática, com vistas a torná-la mais compreensível, assim como uma descrição mais detalhada de suas características (Gil, 2017). Sampieri, Collado e Lúcio (2006) afirmam que as pesquisas exploratórias visam examinar um tema pouco estudado, enquanto a pesquisa descritiva busca especificar propriedades e características importantes do fenômeno analisado.

Foi desenvolvido seguindo abordagem que se assenta predominantemente numa perspectiva qualitativa e dialética, seguindo os movimentos e contradições próprios dos espaços educativos. Segue orientação naquilo que Minayo (2016) salienta, ou seja, a pesquisa qualitativa trabalha com o universo de significados, motivos, aspirações, crenças, valores e atitudes, o que corresponde a um espaço mais profundo das relações, dos processos e dos fenômenos que não podem ser reduzidos à operacionalização de variáveis.

Contou com pesquisa bibliográfica que fundamenta e orienta o trabalho, realizada a partir de material publicado, com incidência em obras de autores como Anastasiou e Alves (2015), Araujo (s.d.), Bordenave e Pereira (2014), Kuenzer (2014), Libâneo (2018), Machado (2008), Nérici (1992), Piletti (2010), Veiga (2017), entre outros. A escolha desses autores reside no fato de que são estudos clássicos em relação ao tema na área da Pedagogia, porém há pouca repercussão no âmbito da Educação Profissional e Tecnológica, razão que justifica o presente ensaio, que busca contribuir nesse sentido.

A busca pelos dados, nas obras referenciais, orientou-se pelas questões mencionadas na introdução, que deram origem as três categorias nas quais está estruturado o ensaio, quais sejam: as singularidades do estudo dirigido, suas repercussões/efeitos e sua aplicação no processo de ensino-aprendizagem.

\section{Singularidades do Estudo Dirigido como Estratégia de Ensino na Educação Profissional e Tecnológica}

Veiga (2017) conceitua o estudo dirigido como uma técnica em que “[...] os alunos executam em aula, ou fora dela, um trabalho determinado pelo professor, que os orienta e os acompanha [...]. O professor oferece um roteiro de estudo previamente elaborado para que o aluno explore o material de maneira efetiva" (Veiga, 2017, p. 80-81). Esse método propõe que o estudante reflita sobre o tema proposto e tenha uma análise crítica sobre o assunto.

$\mathrm{O}$ estudo dirigido é uma estratégia de ensino que exige a capacidade dos estudantes de aprender por esforço próprio guiado por material didático projetado pelo professor para esse fim. Requer roteiros previamente traçados para a exploração efetiva do material para que o estudante aprenda a estudar de forma independente, desenvolvendo habilidades que envolvem leitura, compreensão, problematização, interpretação, associação de ideia, reflexão crítica, elaboração de sínteses, realização de exercícios de avaliação, formulação de conclusões, em vez da memorização de uma quantidade de informações (Veiga, 2017).

Com o acompanhamento do professor, os estudantes realizam atividades intelectuais orientadas para a promoção da aprendizagem de conteúdos e para o exercício de situações de estudo que colaboram para o desenvolvimento de múltiplas 
habilidades (identificar, selecionar, comparar, experimentar, analisar, concluir, solucionar problemas, por exemplo), respeitando o estilo e o ritmo de aprendizagem.

Esta estratégia de ensino, portanto, pode contribuir para o ensino da EPT, uma vez que se espera que o professor que nela atua,

[...] deve ser capaz de permitir que seus alunos compreendam, de forma reflexiva e crítica, os mundos do trabalho, dos objetos e dos sistemas tecnológicos dentro dos quais estes evoluem; as motivações e interferências das organizações sociais pelas quais e para as quais estes objetos e sistemas foram criados e existem; a evolução do mundo natural e social do ponto de vista das relações humanas com o progresso tecnológico; como os produtos e processos tecnológicos são concebidos, fabricados e como podem ser utilizados; métodos de trabalho dos ambientes tecnológicos e das organizações de trabalho. Precisa saber desenvolver comportamentos pró-ativos e socialmente responsáveis com relação à produção, distribuição e consumo da tecnologia (Machado, 2008, p. 15).

Por meio do estudo dirigido, o professor poderá superar práticas tradicionais de ensino que se encontram presentes na EPT e criar condições para transformar as atividades formais do exercício pedagógico tornando o processo ensinoaprendizagem mais atraente e envolvente, estimulando a apropriação do conhecimento, reelaboração reflexiva dos conceitos e experiências úteis para a vida e prática educacional. Na EPT pode ser uma interessante estratégia, dependendo de para que se prepare e de como se prepara. O sucesso de sua preparação depende da maneira pela qual é encarada a atividade de preparar o emprego dessa técnica (Veiga, 2017).

Para Piletti (2010), o estudo dirigido se fundamenta no princípio didático de que o professor não ensina e, sim, ajuda o estudante a aprender. Essa técnica consiste na solicitação de uma tarefa ao estudante mediante o fornecimento de instruções claras e simples sobre como realizá-la. É realizado com o suporte de roteiros previamente traçados pelo professor. Pode partir da leitura de um ou mais textos escolhidos pelo professor, sobre os quais os estudantes, seja individualmente ou em grupo, trabalharão de forma ativa na interpretação e análise do conteúdo (Nérici, 1992). “[...] Se fundamenta na atividade do educando e se efetiva na situação socioindividualizada em sala de aula ou fora dela, mas, sempre sob a direção do professor, que exerce um papel insubstituível na condução do processo de ensino do qual os estudantes participam” (Veiga, 2017, p. 80).

Na EPT, o estudo dirigido pode partir do desenvolvimento de uma atividade prática planejada e solicitada pelo professor, onde o estudante ou grupo de estudantes se envolverão e analisarão as operações realizadas, respondendo criticamente as indagações emitidas pelo professor. Proporciona ao estudante o estudo de um tema ou desenvolvimento com base em roteiro elaborado pelo professor. Oferece condições de participação do estudante, ao solicitar dele a busca de respostas a questionamentos, direcionadores à aprendizagem de habilidades, atitudes e valores necessários para o desempenho de atividades requeridas pelo mundo do trabalho. Pode ser empregado em qualquer componente curricular da formação profissional, introduzindo um conteúdo novo ou reforçando um assunto já trabalhado. Contribui para tornar o estudante independente do professor, orientando-o para estudos futuros e participação na sociedade. Consolida conhecimentos por meio de uma combinação da explicação do professor com exercícios e busca soluções para problemas por meio de questões que os estudantes possam resolver criativamente e de forma independente.

Por meio do estudo dirigido é possível desenvolver a capacidade de compreensão do processo tecnológico em suas causas e efeitos e incentivar a produção, a inovação científico-tecnológica e suas respectivas aplicações no mundo do trabalho. Auxilia no desenvolvimento de competências profissionais tecnológicas, gerais e específicas, para a gestão de processos e a produção de bens e serviços. Para o estudante da EPT, a aprendizagem se processa pelo seu próprio esforço. Para o professor, o ensino está ocorrendo desde a escolha do recurso que será utilizado (texto, vídeo, atividades práticas), a elaboração do roteiro, o acompanhamento e as orientações aos estudantes durante a sua execução, no momento da correção e na análise das respostas. 


\section{Repercussões para o Processo Ensino-Aprendizagem da Educação Profissional e Tecnológica}

O estudo dirigido é uma das estratégias de ensino que pode ser utilizada de forma recorrente na docência da EPT fundamentada no princípio didático de que o professor não ensina diretamente: ele é o agilizador da aprendizagem, ou seja, ajuda o estudante a aprender. É o incentivador e o ativador do aprender. De maneira especial, essa técnica põe em evidência o modo como o estudante aprende. Pode atender às exigências do processo ensino-aprendizagem da EPT, uma vez que, utilizando-se de dados reais contidos nas diferentes áreas do conhecimento, incentiva a atividade intelectual do estudante, força-o à descoberta de seus próprios recursos mentais, facilitando-lhe o desenvolvimento das habilidades e operações de pensamento significativas e possibilitando-lhe ajustar-se às tarefas que deve executar para alcançar o previsto nos objetivos.

$\mathrm{Na}$ EPT, a utilização do estudo dirigido estimula o estudante à criatividade, uma vez que exige pensamento reflexivo, sendo que, de acordo com o contexto, provoca a necessidade de inventar, buscar modos pessoais de operar com inteligência e resolver o que lhe foi proposto. Para Anastasiou e Alves (2015, p. 84), o estudo dirigido

Possibilita aos estudantes estudos específicos do conteúdo em defasagem, desenvolve a reflexão e capacita-os à retomada, individual ou coletiva, dos aspectos pontuais não dominados anteriormente. Pode se tornar um importante recurso didático que auxilia o professor a lidar com as diferentes sínteses trazidas pelos estudantes no início da programação pretendida, substituindo ações habitualmente chamadas de "nivelamento" para entrada em novos níveis de complexidade dos conteúdos.

Além deste enfoque apontado por Anastasiou e Alves (2015), o estudo dirigido pode contribuir para a dinâmica do processo ensino-aprendizagem da EPT que deve

[...] Oportunizar situações de aprendizagem que possibilitem a articulação entre teoria e prática, lembrando que esta, contudo, só pode ser apropriada através do movimento do pensamento, ou seja, da atividade teórica, que se constitui na especificidade das práticas escolares. É através dela que o pensamento transita continuamente entre o abstrato e o concreto, entre a forma e o conteúdo, entre o imediato e o mediato, entre o simples e o complexo, entre o que está dado e o que se anuncia (Kuenzer, 2014, p. 31).

Este movimento que se evidencia nas inter-relações do processo educativo da EPT e de outros processos sociais está sendo considerado cada vez mais necessário como componente estratégico para a construção da cidadania e para a introdução de jovens e trabalhadores nos mundos do trabalho, pleno de transformações e marcado pelos avanços tecnológicos.

Para isso, novas formas de relação entre conhecimento, produção e sociedade se constituem, em face das transformações sociais que afetam a vida das pessoas. Uma dessas formas está presente nas instituições de ensino de EPT onde as práticas pedagógicas deverão progressivamente se transformar, propiciando a aquisição de princípios científicos gerais, habilidades instrumentais básicas e condições de reconhecimento que facilitam a compreensão histórico-crítica da sociedade e das formas de atuação do ser humano. Para Gabriel, Silva e Freire (2018, p. 121),

As funções do estudo dirigido são a concretização dos conhecimentos por meio das orientações dadas pelo professor e a busca de solução de problemas através dos questionamentos advindos dos próprios alunos. Desse movimento, entende-se a construção de um "novo aluno", aquele estudante com mais criatividade, autonomia e criticidade.

O estudo dirigido pode contribuir para o desenvolvimento do processo ensino-aprendizagem envolvido por esses princípios. Apoiado nas ideias de Libâneo (2018), esta estratégia de ensino pode contribuir para a EPT

- desenvolver habilidades e hábitos de trabalho de forma independente e criativo;

- sistematizar e consolidar conhecimentos, habilidades e hábitos; 
- possibilitar aos estudantes condições para resolver problemas, vencer dificuldades e desenvolver métodos próprios de aprendizagem;

- proporcionar aos estudantes o desenvolvimento da capacidade de trabalhar, de forma livre e criativa, com os conhecimentos adquiridos, aplicando-os a situações novas, referentes a problemas cotidianos da sua vivência e a problemas mais amplos da vida social;

- propiciar ao professor a observação de cada estudante em suas dificuldades e progressos, bem como a verificação da eficácia do seu próprio trabalho na condução do ensino.

Considerando que a EPT lida com conhecimentos de diferentes naturezas e especificidades: conhecimentos factuais, conceituais, princípios e processos (Vieira; Vieira; Pasqualli, 2017), o estudo dirigido poderá ainda fornecer delineamento didático para o estudante realizar sua aprendizagem, ao mesmo tempo em que oferece técnicas e consciência de como estudar. O professor deve se manifestar como orientador e facilitador da aprendizagem para que o estudante resolva de modo um tanto independente e criador a tarefa determinada. Tanto o professor quanto o estudante precisam seguir às condições prévias de estudo, planejamento e organização para participar do estudo dirigido (Libâneo, 2018).

Para o estudante da EPT, uma das condições é dominar técnicas, tais como saber procurar conhecimentos, utilizandose de recursos variados, ler, analisar, resumir, compreender, expor os resultados, havendo necessidade de reforços nessa área para que o estudo flua sem obstáculos. Deve ainda compreender técnicas diversificadas que são utilizadas na produção e se concentrar em modalidades fundamentais que dão base à multiplicidade de processos e técnicas existentes nos mundos do trabalho, em que o conhecimento científico, o tecnológico e o histórico se encontram devidamente articulados visando à formação humana dos estudantes e, também dos professores.

Nessa prática de transformação, o estudo dirigido pode se constituir numa atividade para desenvolver habilidades e saberes tão necessários na sociedade atual, tanto para o estudante como para o professor da EPT. Para Libâneo (2018), o estudo dirigido apresenta duas funções principais:

a) A consolidação dos conhecimentos por meio de uma combinação da explicação do professor com a realização de exercícios;

b) A busca de solução de problemas por meio de questões que os estudantes possam resolver criativamente e de forma independente.

O estudo dirigido pode ser aplicado de forma individualiza ou em grupo, dentro e fora de sala de aula. Pode partir de um estímulo comum como por exemplo a utilização do texto. Sofre influência de teorias da educação, como a da Escola Nova, onde encontra seus pressupostos iniciais; do Tecnicismo, no qual foi adotado como meio passivo de transmissão de conteúdo, baseado nos princípios da racionalidade, na eficiência e da produtividade, nos anos 60 e da Pedagogia Crítica, em que encontrou utilização como meio de construção de novos conhecimentos como meio ativo, orientado por princípios de individualidade, liberdade e espontaneidade, possibilitando atividades como "aprender fazendo" e "aprender a aprender". Na sua utilização, o professor deve ter consciência que se trata de uma estratégia que exige a participação dos estudantes, no qual estimula o desenvolvimento do pensamento reflexivo, da análise crítica, em vez da memorização de uma grande quantidade de informações (Veiga, 2017).

Os objetivos dessa técnica de ensino são:

a) provocar os alunos criticamente a respeito do que a realidade indica, buscando na leitura os fundamentos necessários à explicação e compreensão das questões levantadas; b) aprofundar o conteúdo do texto didático para além das informações superficiais e de mera opinião; c) buscar conexão entre o texto didático e seu contexto, vinculando também ao contexto do autor e do leitor, ou seja, propiciar a leitura polissêmica ('processo de significação lugar de sentidos') (Orlandi 1983, p. 80); d) desenvolver no aluno a reflexão, a criticidade e a criatividade e e) 
capacitar os alunos à leitura de textos ou livros didáticos necessários à sua instrumentalização, ou seja, apropriação das ferramentas de caráter histórico, matemático, científico, literário, artístico, tecnológico etc. (Veiga, 2017, p. 81).

Nessa mesma direção Piletti (2010, p. 127) apresenta outros objetivos de estudo dirigido que merecem ser destacados:

a) Criar, corrigir e aperfeiçoar hábitos de estudos; b) servir como técnica de fixação, integração e ampliação da aprendizagem; c) proporcionar condições para o aluno aprender através de sua própria atividade, dando-lhe condições de progredir em seu próprio ritmo; d) favorecer o atendimento das diferenças individuais; e) desenvolver a habilidade de adquirir informações pela leitura de texto e f) favorecer o sentimento de independência e de segurança.

Por fim, tendo como referência os apontamentos de Veiga (2017) e Bordenave e Pereira (2014), é possível afirmar que o estudo dirigido apresenta os seguintes propósitos:

a) Desenvolver técnicas e habilidades de estudo, ajudando o estudante a aprender as formas mais adequadas e eficientes de estudar cada área do conhecimento;

b) Promover a aquisição de novos conhecimentos e habilidades, ajudando o estudante no processo de construção do conhecimento;

c) Oferecer aos estudantes um roteiro ou guia de estudos contendo questões, tarefas ou problemas significativos que mobilizem seus esquemas operatórios de pensamento, contribuindo para o aperfeiçoamento das operações cognitivas;

d) Desenvolver nos estudantes uma atitude de independência frente a aquisição do conhecimento e favorecer o sentimento de autoconfiança pelas tarefas realizadas, por meio da própria atividade e do esforço pessoal;

e) Aprofundar o conteúdo do texto didático para além das informações superficiais e de mera opinião;

f) Desenvolver no estudante a reflexão, a criticidade e a criatividade.

\section{Planejando o Estudo Dirigido na Educação Profissional e Tecnológica}

Bordenave e Pereira (2014) sugerem uma lista de perguntas que pode auxiliar o professor da EPT no planejamento do estudo dirigido:

- Objetivos: a) quais são as habilidades intelectuais que a estratégia de ensino e aprendizagem colaborará para desenvolver? b) quais são os conteúdos/conceitos a serem mobilizados com o suporte da estratégia de ensino e aprendizagem?

- Seleção de texto: a) o conteúdo do texto aprofunda e detalha o tema previsto no módulo? b) quais conteúdos estão relacionados com a unidade de ensino e aprendizagem e com o que os estudantes precisam? c) a linguagem utilizada pelo autor é adequada ao leitor (o grupo de estudantes)? d) o tema, a abordagem e a linguagem contribuem para despertar o interesse dos leitores (os estudantes)? e) como explorar o texto escolhido com os estudantes?

- Análise do texto: a) quais são os termos novos? b) quais conhecimentos novos o autor traz de forma clara? c) quais conhecimentos novos exigem explicação? d) quais são as possibilidades dos estudantes fazerem associações? e) quais são as possibilidades dos estudantes estabelecerem relações e raciocinar? f) qual é a extensão do texto? g) qual é a necessidade de fazer adaptação, condensação ou estruturação?

- Elaboração das questões: a) orientar a leitura quanto a terminologia, fatos, conceitos, classificação, análise, crítica; b) orientar a assimilação dos conhecimentos e o desenvolvimento de habilidades, mediante a formulação de perguntas que exijam respostas que requeiram elaboração mental, classificação, formulação de esquema, relação entre fatos etc., explicação dos termos, sínteses, elaboração de conceitos próprios, extrapolação, interpretação de símbolos, legenda, gráficos, crítica ou avaliação e associação de conhecimentos adquiridos anteriormente requerendo o uso de habilidades intelectuais. Podem ser usadas questões abertas, ordens diretas, perguntas de múltipla escolha, perguntas do tipo verdadeiro falso, técnica de lacunas, etc. 
Para que o estudo dirigido cumpra sua função didática, são necessários alguns pré-requisitos relacionados ao professor e ao estudante (Libâneo, 2018):

- Relativas ao professor: a) escolher tarefas claras, compreensíveis e adequadas aos conhecimentos e capacidades do estudante; b) assegurar condições do ambiente que favoreçam a realização das atividades envolvidas; c) acompanhar de perto e às vezes individualmente as atividades realizadas pelos estudantes; $d$ ) aproveitar o resultado das atividades para compartilhar com os demais estudantes da turma.

- Relativas aos estudantes: a) saber o que e como desenvolver as atividades requeridas; b) dominar as técnicas do trabalho (saber buscar, utilizando-se de recursos variados, ler, resumir, expor os resultados etc.); c) desenvolver atitudes de ajuda mútua, pedindo e recebendo auxílio não somente do professor, mas também dos colegas.

Dentre as principais atividades que podem ser realizadas no contexto de um estudo dirigido, Bordenave e Pereira (2014) destacam:

- Pesquisas bibliográficas: o professor orienta a seleção de textos, eventualmente de materiais auxiliares, fazendo observações e intervenções oportunas na medida em que os estudantes evoluam no trabalho.

- Compreensão e avaliação dos assuntos trabalhados: o professor orienta os estudantes quanto a melhor forma de estudar: como ler? reconhecer a ideia principal? situar a base teórica explorada? identificar os argumentos utilizados pelo autor? elaborar esquemas? desenvolver resumos? etc.

- Tentativa de solução de uma situação: trabalho com situações-problema junto aos grupos de estudantes a fim de que busquem soluções para as questões propostas.

\section{Implementando o Estudo Dirigido na Educação Profissional e Tecnológica}

Para a aplicação do estudo dirigido, recomenda-se que o estudante seja orientado para outras fontes de consulta, além da explanação e da referência recomendada/elaborada pelo professor. O roteiro de estudos ou as perguntas devem estar relacionados aos objetivos do assunto e numa sequência ordenada. O professor deverá prestar assistência aos estudantes durante toda a aplicação do estudo dirigido, sem, no entanto, interferir nas respostas, a não ser para esclarecer dúvidas.

Sua aplicação requer preparação que inicia (primeiro princípio) com a organização de um roteiro que abrange indicação de fontes, instruções objetivas, delimitação de tarefas, passando por observar princípios básicos para a escolha do material de leitura como complexidade do texto. A qualidade do material escrito é o segundo princípio e tem como objetivo ser a fonte da informação e o meio apropriado para aplicação da técnica. $O$ terceiro princípio trata da adequação do público envolvido, o texto deve ser potencialmente significativo para os estudantes. O último princípio trata de uma questão fundamental que é a atualização do material escolhido, sendo imprescindível para a fixação e integração de conteúdos e pode substituir explicações expositivas pelo professor (Veiga, 2017).

Vários componentes curriculares e objetivos/conteúdos podem se beneficiar das atividades propostas no estudo dirigido, desde que sua organização e seus objetivos estejam bem definidos, assim como um roteiro claro e bem delineado direcionado aos estudantes.

Em se tratando da EPT, as tarefas propostas no estudo dirigido podem ser diversificadas, tais como:

a) Ler e interpretar um texto respondendo às perguntas;

b) Desenvolver experiências e atividades práticas, observando, seguindo as etapas e fazendo anotações até a conclusão;

c) Assistir filmes, vídeos ou documentários, anotando pontos principais (conforme orientação do professor);

d) Observar imagens (fotos e cartazes), estabelecendo relação e comparação; 
e) Ler situações-problema (desafios) e estudos de casos, podendo expressar graficamente sua interpretação e conclusão sobre o proposto.

A utilização de tarefas em forma de estudo dirigido permitirá ao estudante aprender a estudar, pois sua organização se utiliza de roteiro seguindo tarefas que se referem à mobilização e ativação de operações mentais.

Bordenave e Pereira (2014) destacam três etapas comuns à atividade científica e que comumente compõem a implementação do estudo dirigido, conforme seguem:

a) Síncrese: solicita-se uma visão global (sincrética) do texto ou atividade, mediante esquemas simples, antecipadamente divulgados pelo professor: tema-título, problema discutido, objetivos justificadores, literatura de suporte, conceitos-chave, resultados etc.

b) Análise: o professor formula questões claras e simples para serem respondidas, seja com base no texto, seja interpretando a ideia ou a intenção do autor, desenvolvendo uma atividade prática, associando ideias, exercitando o raciocínio e a imaginação e desenvolvendo a criatividade.

c) Síntese: com base no que o estudante leu e assimilou, o professor propõe problemas práticos a serem resolvidos. Além disso, solicita a formulação de conclusões, requerendo complementações da pesquisa, quando for possível.

Nesta mesma direção, Piletti (2010) apresenta apontamentos e ressalta que são necessários alguns cuidados na elaboração e aplicação da técnica de estudo dirigido, ou seja:

a) A atividade ou o texto a ser utilizado deve ser simples, abrangente, relevante, na extensão apropriada, e as questões não devem exigir a mera repetição do texto;

b) Pode ser realizado nas dependências da instituição de ensino ou em casa, porém, é importante a assistência do professor na sua execução, correção e avaliação;

c) As questões devem desenvolver no estudante a capacidade de análise, síntese, interpretação, ordenação, avaliação, etc.

As atividades sugeridas no estudo dirigido devem demonstrar a complexidade que é ler e interpretar um texto, que requer ações como sublinhar ideias, destacar partes importantes, esquematizar o texto, registrar observações, identificar conceitos, características, pesquisar significados de palavras desconhecidas, elaborar gráficos sobre o assunto lido, identificar divergências de ideias, analisar, julgar e propor soluções, elaborar questionamentos, estimular ideias complementares, comparar o conteúdo com a sua realidade, elaborar suas próprias conclusões, justificar posicionamentos e argumentar com o autor. A técnica aplicada em grupo requer ações como debater criticamente o tema, identificar ideologias, provocar conflito intelectual e descobrir implicações sociais e políticas no texto. Devem, os estudantes, registrar, em forma de síntese, por grupo e, finalmente, debater num grande grupo as sínteses e elaborar a síntese das sínteses (ibid.).

O professor não deve assumir posturas autoritárias e espontaneístas, mas democrática, responsável e diretiva. Como dirigente do processo ensino-aprendizagem, ele não deve esquecer que a regra é a atividade do estudante, para o estudante e com o estudante (Veiga, 2017). O acompanhamento se dará pela produção que o estudante for construindo na execução das atividades propostas, nas questões que formula ao professor, nas revisões que este lhe solicita, a partir do que vai se inserindo gradativamente nas atividades do grupo a que pertence. Trata-se de um processo avaliativo eminentemente diagnóstico, sem preocupação classificatória (Anastasiou e Alves, 2015).

Bordenave e Pereira (2014) apresentam algumas proposições que podem ajudar o professor na elaboração e aplicação do estudo dirigido, conforme seguem:

a) Organize o estudo dirigido considerando os objetivos educacionais propostos, a natureza do conteúdo a ser desenvolvido e as habilidades cognitivas e operações mentais a serem praticadas. O estudo dirigido deve estar integrado à 
dinâmica da unidade estudada e às demais técnicas utilizadas. Deve também estar adequado ao tempo disponível para cada aula ou sessão de estudo.

b) Verifique quais são os conhecimentos e habilidades que os estudantes devem adquirir em determinado conteúdo e organize tarefas operatórias que favoreçam a construção das habilidades e conhecimentos previstos.

c) Elabore, de forma clara e objetiva, as instruções e orientações escritas do roteiro para o estudo dirigido, explicitando as tarefas operatórias que o estudante vai executar, de modo que o enunciado das perguntas ou questões seja compreensível para ele.

d) Distribua o roteiro ou guia de estudo para os estudantes deixando-os trabalhar com uma margem de tempo suficiente. De vez em quando, percorra a classe observando os estudantes e esclarecendo as possíveis dúvidas.

e) Solicite que os estudantes, terminado o tempo de estudo, apresentem o resultado do seu trabalho para a classe. Cada item do estudo dirigido pode ser apresentado por um ou mais estudantes. A apresentação deve ser seguida da análise e discussão por parte dos demais.

Na busca de indicativos para implementar o estudo dirigido na EPT, pode-se destacar ainda que o estudo dirigido pode substituir a apresentação do professor por um trabalho de pesquisa dos próprios estudantes, pressupondo a diretividade por parte dele e atividade dos estudantes, em sala de aula ou fora dela, onde estes executam um trabalho determinado pelo professor, que os orienta e os acompanha, valendo-se de um capítulo do livro, um artigo, um texto didático, um determinado livro, uma atividade prática. O professor deve oferecer um roteiro de estudo previamente elaborado para que o estudante explore a atividade proposta, lendo, compreendendo, interpretando, analisando, comparando, aplicando, avaliando e elaborando. Procedendo dessa forma, a percepção que o estudante tem de determinado tema, associado à leitura que ele faz, possibilita-o a elaborar e construir novos conhecimentos.

De acordo com Burnier (2005), o que caracteriza o estudo dirigido é o roteiro que deve ser elaborado pelo professor. Por meio desse roteiro, o estudante vai estudar aquilo que o professor iria ministrar em sala de aula. Ao invés de o professor "dar a aula", os estudantes é que deverão produzir, mas dentro dos estritos limites desejados e determinados pelo professor, de profundidade e extensão. O que marca o estudo dirigido, bem como a tarefa dirigida, é, pois, o roteiro elaborado pelo professor. Desse modo, essa técnica consiste em fazer o aluno estudar um assunto a partir de um roteiro elaborado pelo professor. Este roteiro estabelece a extensão e a profundidade do estudo (Haydt, 2006).

Ao se trabalhar com o estudo dirigido na EPT, deve-se estimular o estudante a aprofundar o conteúdo em desenvolvimento para além das informações superficiais e da mera opinião, buscando a correlação entre o texto didático, seu contexto, vinculando também ao contexto do leitor, estimulando nele, a reflexão. Ao trabalhar com esta técnica de ensino, o professor tem a oportunidade de desenvolver nos estudantes o espírito crítico quanto à seletividade na busca da leitura e da informação, detendo-se naquilo que possa acrescentar alguma coisa para o seu conhecimento.

\section{E, Para Concluir... Algumas Considerações}

A produção deste ensaio mostrou que a utilização da estratégia, técnica ou dinâmica de ensino denominada estudo dirigido favorece o desenvolvimento de práticas educativas na EPT porque estimula a aprendizagem autônoma e significativa tendo o estudante como o protagonista das atividades realizadas, desenvolvendo temas de seu interesse, aprendendo a aprender, descobrindo o prazer para aprender e sendo sujeito de suas ações.

Trata-se de uma estratégia que permite desenvolver temas da EPT e de interesse do estudante, estimula o prazer em estudar e o incentiva a ser o sujeito de seu aprendizado. Possui peculiaridades que exigem habilidades e competências dos professores e estudantes para a obtenção de resultados satisfatórios no processo ensino-aprendizagem. Evidencia os conhecimentos, as habilidades e as atitudes dos estudantes para a compreensão, análise crítica e desenvolvimento de 
atividades, projetos e ações que visam explorar de diferentes formas e por vários ângulos o conteúdo que está sendo trabalhado.

É uma técnica que apresenta duas funções principais: a primeira é de consolidação dos conhecimentos por meio de uma combinação da explicação do professor com exercícios. A segunda, é a busca da solução dos problemas por meio de questões que os estudantes possam resolver criativamente e de forma independente. O professor atua como um orientador e mediador da aprendizagem para que o estudante resolva de modo relativamente independente e de forma criativa os desafios que foram propostos. É importante que ambos (estudantes e professores) atuem de forma responsável e sigam o planejamento e a organização proposta para o desenvolvimento do estudo dirigido, a fim de que a os conteúdos, as atividades e as estratégias de avaliação sejam desenvolvidas conforme o cronograma previsto para o desenvolvimento da atividade.

Pode ser realizado tanto em casa como em sala de aula. Sua prática deve ser iniciada na presença do professor por meio de um roteiro, facilitando, assim, o processo de execução das tarefas, incentivando os estudantes e fornecendo subsídios para que compreendam o objetivo e possam conquistar a autonomia necessária. Independentemente do local onde seja realizada a atividade, após concluída, o acompanhamento do professor é indispensável para promover a troca de experiências no momento da correção. Este deve intervir quando necessário, avaliando não somente o que o estudante compreendeu, mas também o auxiliando no planejamento futuro.

Por fim, pode-se assegurar que o estudo dirigido é uma estratégia de ensino que permite ampliar as possibilidades de ensino e aprendizagem na EPT, considerando as condições dos estudantes, dos professores e da instituição de ensino, provocando os estudantes a pensarem criticamente sobre a realidade.

Dada a importância do tema, espera-se que o presente trabalho, por suas limitações, estimule novas investigações, dando continuidade ao presente estudo, que pode incluir estudos com estudantes e professores desta modalidade e forma de ensino, analisando seus posicionamentos diante da citada estratégia de ensino e o impacto da sua utilização no desenvolvimento do processo ensino-aprendizagem.

\section{Referências}

Anastasiou, L. G. C. \& Alves, L. P. (Org.) (2015). Processos de ensinagem na universidade: pressupostos para as estratégias de trabalho em aula. 9. ed. Joinville: Univille.

Araujo, R. M. L. (S.D.). As práticas formativas em educação profissional no estado do pará: em busca de uma didática da educação profissional. Projeto de pesquisa. Brasília: CNPQ - Conselho Nacional de Desenvolvimento Científico.

Bordenave, J. D.; Pereira, A. M. (2014). Estratégias de ensino-aprendizagem. 33. ed. Petrópolis: Vozes.

Brasil (1996). Ministério da Educação. Lei de Diretrizes e Bases da Educação Nacional. Brasília(DF): Imprensa Nacional.

Burnier, S. et al. (2007). Histórias de vida de professores: o caso da educação profissional. Revista Brasileira de Educação, Rio de Janeiro: ANPEd; Campinas: Autores Associados, v. 12, n. 35, p. 343-358. http://www.scielo.br/pdf/rbedu/v12n35/a13v1235.pdf.

Burnier. S. (2005). Técnicas de ensino. Belo CEFET-MG. https://www.leticiacapelao.com/arquivos/profissional/Apostila\%20T\%E9cnicas\%20de\%20Ensino.pdf

Gabriel, A. G. P.; Silva, J. S.; Freire, E. J. (2018). A utilização da investigação, do estudo dirigido e do estudo de texto como estratégias de ensino: um caso particular numa instituição de ensino superior (IES) no município de Alta Floresta - MT. Revista Pedagogia em Foco, Iturama (MG), 13(9), 112-129. https://revista.facfama.edu.br/index.php/PedF/article/view/331.

Gil, A. C. (2017). Como elaborar projetos de pesquisa. 6. ed. São Paulo: Atlas.

Haydt, R. C. C. (2006). Curso de didática geral. São Paulo: Ática.

Kuenzer, A. Z. (2014). As relações entre o mundo do trabalho e a escola: práticas de integração. In: Rios, F. H., Costa, R. R. S. \& Urbanetz, S. T. Educação profissional: desafios e debates [recurso eletrônico]. Curitiba: Instituto Federal do Paraná. (Coleção formação pedagógica; v. 1).

Kuenzer, A. Z. (2004). Competência como práxis: os dilemas da relação entre teoria e prática na educação dos trabalhadores. Boletim técnico do SENAC, 29(1), 17-27.

Libâneo, J. C. (2018). Didática. 2. ed. São Paulo: Cortez. 
Research, Society and Development, v. 10, n. 12, e151101220242, 2021

(CC BY 4.0) | ISSN 2525-3409 | DOI: http://dx.doi.org/10.33448/rsd-v10i12.20242

Libâneo, J. C. (2002). O essencial da didática e o trabalho de professor em busca de novos caminhos. In: Libâneo, J. C. Didática: velhos e novos temas. Goiânia: Edições do Autor. https://docplayer.com.br/17119935-O-essencial-da-didatica-e-o-trabalho-de-professor-em-busca-de-novos-caminhos.html.

Machado, L. R. S. (2008). Diferenciais inovadores na formação de professores para a Educação Profissional. Revista Brasileira da Educação Profissional e Tecnológica, 1(1), 8-22.

Machado, L. R. S. (2010). Ensino médio e técnico com currículos integrados: propostas de ação didática para uma relação não fantasiosa. In: Moll, J. (org.). Educação profissional e tecnológica no Brasil contemporâneo: desafios, tensões e possibilidades. Porto Alegre: Artmed.

Minayo, M. C. S. (org.) (2016). Pesquisa social: teoria, método e criatividade. Rio de Janeiro: Vozes.

Nérici, I. G. (1992). Didática geral dinâmica. 11. ed. São Paulo: Atlas.

Okane, E. S. H. (2004). O estudo dirigido como estratégia de ensino na educação profissional em enfermagem (Dissertação de Mestrado) - Escola de Enfermagem, Universidade de São Paulo, São Paulo. https://www.teses.usp.br/teses/disponiveis/7/7131/tde-28112006-092943/publico/Elaine_Suemi.pdf.

Piletti, C. (2010). Didática geral. 24. ed. São Paulo: Ática.

Ramos, M. N. (2014). Filosofia da práxis e práticas pedagógicas de formação de trabalhadores. Trabalho \& Educação, Belo Horizonte, 23, 207-218. https://periodicos.ufmg.br/index.php/trabedu/article/view/9306.

Sampieri, R. H., Collado, C. F. \& Lucio, M. P. B. (2006). Tipos de Pesquisa. In: Metodologia da pesquisa. 3. ed. São Paulo: McGraw-Hill.

Veiga, I. P. A. (Org.) (2017). Técnicas de Ensino: porque não? 21. ed., São Paulo: Papirus.

Vieira, J. A., Vieira, M. M. M. \& Pasqualli, R. (2017). Estudo de caso como estratégia de ensino para a educação profissional e tecnológica. Série-Estudos, 22(44), 143-159. https://www.serie-estudos.ucdb.br/serie-estudos/article/view/1012. 